\title{
Effect of Preliminary Selection of RC Shear Walls' Ductility Level on Material Quantities
}

CrossMark

\author{
Hossam El-Sokkary ${ }^{1,2}$ (1) and Khaled Galal ${ }^{1 *}$ (B)
}

\begin{abstract}
According to the National Building Code of Canada, the seismic force resisting systems (SFRS) of reinforced concrete (RC) buildings are classified based on their ductility level as being ductile, moderately ductile and conventional construction systems. The selection of the ductility level of an SFRS at the conceptual design phase is primarily governed by the seismicity at the building location, the building dynamic characteristics, and the height limitations specified by the design code. The selected ductility level affects the design loads, the cross-sections and reinforcement of the SFRS components, and hence the overall construction cost. This paper aims to evaluate the effect of the wall's selected ductility level on the quantities of its constituent materials as well as the rebar detailing. Four multi-storey RC shear wall buildings with different heights located in three different cities in Canada; Toronto, Montreal, and Vancouver, were selected to represent three different seismic hazard zones (low, medium, and high). For each building height and location, the walls were designed using the dynamic analysis procedure of the National Building Code of Canada to reach different ductility levels. The construction material quantity estimates were evaluated and compared to a reference case for each building height, seismic hazard and ductility level. The effect of ductility level on the bars detailing is also investigated. This paper helps the structural engineers to select the cost-effective and constructible RC shear wall system at the conceptual design phase before reaching the detailed design phase.
\end{abstract}

Keywords: conceptual design phase, reinforced concrete, shear walls, ductility, dynamic analysis, material quantities

\section{Introduction}

Current seismic design codes allow nonlinear response of the seismic force resisting system (SFRS). This nonlinear response permits the SFRS to experience higher deformations that will dissipate the earthquake energy at a reduced design force level, and hence would lead to smaller sections of the system. The National Building Code of Canada (NBCC 2010) allows three levels of ductility for reinforced concrete (RC) shear wall buildings; conventional construction, moderately ductile and ductile walls. As the wall level of ductility increases, the design seismic force decreases and stricter detailing, ductility and stability requirements are imposed

\footnotetext{
*Correspondence: khaled.galal@concordia.ca

1 Department of Building, Civil and Environmental Engineering, Concordia University, 1515 St. Catherine West, Montreal H3G 2W1, Canada

Full list of author information is available at the end of the article Journal information: ISSN 1976-0485 / eISSN 2234-1315
}

by the code (Fig. 1). Despite the fact that the product of the ductility-related force modification factor, $R_{d}$, and the overstrength-related force modification factor, $R_{0}$, is $3.5 \times 1.6=5.6$ for ductile $R C$ shear walls and $2.0 \times 1.4=2.8$ for moderately ductile $\mathrm{RC}$ shear walls, in some situations, designing the wall as a ductile system can result in a less economic design without any advantage over the moderately ductile, or even conventional RC walls. This is due to the elaborated stability and ductility requirements in the ductile wall design, which might not be necessary for the particular building and seismic hazard zone under consideration. Therefore, selection of the most suitable RC shear wall system and its level of ductility at the conceptual design stage is an important decision that can reduce the construction cost significantly. Moreover, the choice of the wall's ductility level affects the building's overall performance and its lateral deformations under design loads. These deformations have to be limited to the code requirements in order not to hinder the building's stability or become 


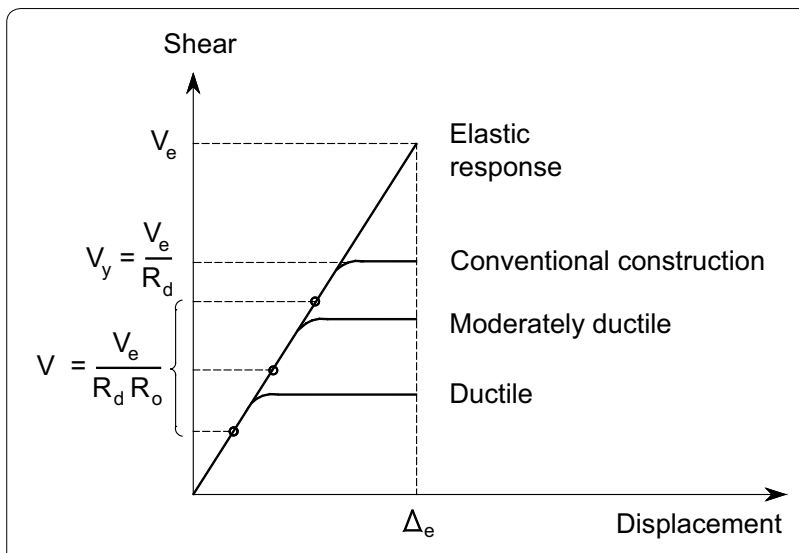

Fig. 1 Seismic force reduction for different levels of ductility.

detrimental to the building's gravity load resisting system and the non-structural elements (Adebar et al. 2010).

According to the NBCC (2010), the analysis for seismic action is to be conducted using the Dynamic Analysis Procedures (DAP), except that under certain conditions, the Equivalent Static Procedures (ESP) may be applied. Although the DAP consume additional engineering time compared to the ESP, in many cases, the three-dimensional dynamic analysis can provide much more economical design. Performing such detailed 3D analysis would not be feasible at the preliminary design stage where the final decision regarding the SFRS and its ductility level is not made yet. The designer decision about the ductility level of an SFRS at the conceptual design phase will affect the cost and constructability of the project (Pullmann et al. 2003). Therefore, it would be beneficial to provide guidelines to the structural engineer for the preliminary selection of the most suitable RC shear wall system and the most efficient ductility level before reaching the detailed engineering phase of the structure.

The selected level of ductility depends on the type of the SFRS, the seismicity of building location, the building dynamic characteristics, and the height limitations of the design code. Adebar et al. (2014) stated that the selection of ductility level for RC shear wall buildings depends mainly on the seismic hazard of the region. They mentioned that conventional, moderately ductile, and ductile walls are the systems of choice in low, medium, and high seismic hazard zones, respectively.

There are several studies that investigated the seismic performance of RC moment resisting frame structures with different levels of ductility (Filiatrault et al. 1998; Heidebrecht and Naumoski 1999; Sadjadi et al. 2007; Galal and El-Sokkary 2008) and the ductility of RC walls (Paulay et al. 1982; Priestley and Park 1987; Wallace 1994; Adebar et al. 2005). However, the literature review showed that the relationship between the ductility level of an SFRS and the construction material quantities or bars detailing has not been sufficiently investigated for RC shear wall buildings in Canada. Hutchison and Van Geldermalsen (1983) compared the cost of ductile RC walls and walls with limited ductility for two building heights (4- and 8-storey buildings) designed according to the New Zealand Code of Practice. They found that a saving of 9 and $10 \%$ of the total building cost was achieved when ductile walls were used for the 4- and 8-storey buildings, respectively. Choopool and Boonyapinyo (2011) studied nine-storey RC moment resisting frames with different levels of ductility and their impact on the construction cost estimates. The frames were designed according to the seismic specifications of Thailand as Ordinary Ductile, Intermediate Ductile, and Special Ductile Frames, and they were compared to the gravity load designed frames. They found that Ordinary Ductile Frame is the most expensive among the ductility levels considered. They also found that the costs of Special and Intermediate Ductile Frames were similar in a low seismic hazard zone due to the requirement for strong column-weak beam.

The objective of this paper is to evaluate the effect of selected SFRS level of ductility on the construction material quantity estimates and the bars detailing of RC shear wall buildings. Four multi-storey RC shear wall buildings with different heights located in three different cities in Canada were selected. Toronto, Montreal, and Vancouver cities were selected to represent low, medium and high seismic hazard zones. 5-, 10-, 15-, and 20-storey buildings were considered in the analyses. For each building height and location, the shear walls were designed according to the NBCC (2010) and the Canadian Standard Association (CSA A23.3-14) (2014) as ductile, moderately ductile, and conventional construction systems. This paper proposes a factor (rebar constructability factor, C.F.) that can reflect the complexity of assembling the wall reinforcement cages which is one of the main concerns affecting the constructability of RC buildings. The construction material quantity estimates and the rebar constructability of each case were evaluated and compared to a reference case. This paper helps the designers for the most suitable selection of ductility level for RC shear wall buildings that satisfies the code requirements, while providing the most economical choice.

\section{Description of the Selected Buildings}

The four buildings selected for this study have the same floor plan that consists of five symmetrical bays in both directions as shown in Fig. 2. The bay width is $5.0 \mathrm{~m}$ with total floor dimensions of $25.0 \mathrm{~m} \times 25.0 \mathrm{~m}$. The storey height is $3.0 \mathrm{~m}$, the slab thickness is $240 \mathrm{~mm}$, and the 

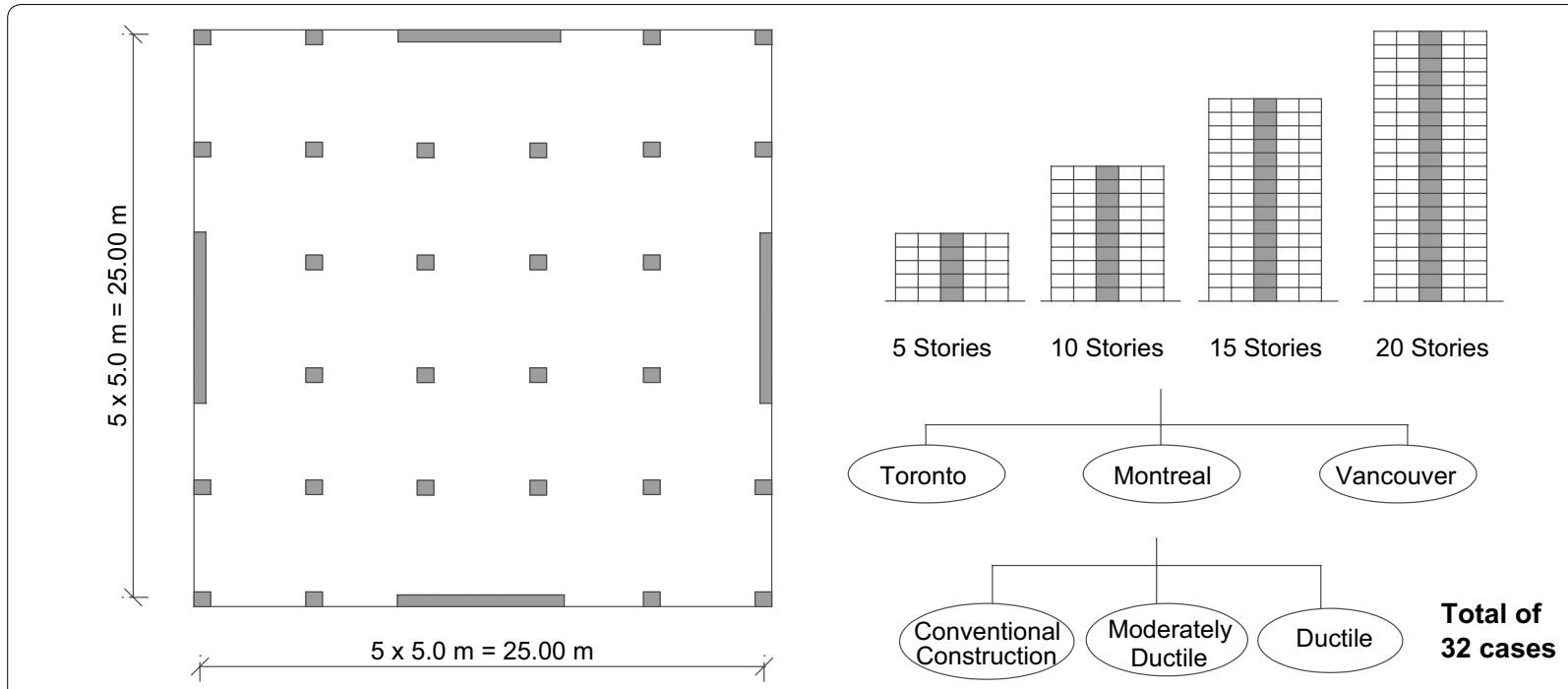

Fig. 2 The floor plan of the studied buildings and the analysis cases.

average flooring and partitions load is $2.0 \mathrm{kPa}$. The slabs were designed to carry a live load equals to $1.9 \mathrm{kPa}$ of a residential occupancy. The buildings are assumed to be founded on very dense soil (Class $C$ ). The design snow load was determined for each city and was found to be $1.12,2.48$, and $1.64 \mathrm{kPa}$ for Toronto, Montreal, and Vancouver, respectively.

The shear walls were chosen to be located at the building extremities in the two orthogonal directions. Two walls were provided in each direction as shown in Fig. 2. The wall dimensions are shown in Table 1, with the largest dimension $\left(\mathrm{L}_{\mathrm{w}}\right)$ being limited to $9.0 \mathrm{~m}$, and a wall thickness $\left(t_{w}\right)$ of $250-400 \mathrm{~mm}$. The shear wall cross-sectional dimensions were maintained along the building height in order to avoid any possible plastic hinging at higher floors. Normal density concrete of a characteristic compressive strength, $\mathrm{f}_{\mathcal{c}}$ of $40 \mathrm{MPa}$ was used, and the yield strength of steel reinforcement, $f_{y}$, was $400 \mathrm{MPa}$. The modulus of elasticity of concrete was taken as 28.4 $\mathrm{GPa}$, the concrete density as $24.0 \mathrm{kN} / \mathrm{m}^{3}$, and concrete Poisson's ratio was taken as 0.2 . It is noted that similar buildings were considered in the literature, e.g., the sample building in the Canadian Concrete Design Handbook (2005) and the numerical study conducted by Boivin and Paultre (2010).

\section{Analysis and Design of Shear Walls \\ 3.1 Analysis Assumptions}

The buildings were modeled using ETABS software (CSI 2013) and response spectrum analyses were performed for prediction of member forces and displacements in the structural systems. The response spectrum method involves the calculation of maximum member forces and displacements for each mode shape using a smooth design response spectrum which is the average of several ground motion records of the location considered. The analyses were conducted using the design response spectra of NBCC (2010) for the three locations considered (Fig. 3). For each building height and location, the shear walls were analyzed according to the Linear Dynamic Analysis and designed to have three different ductility levels (ductile, moderately ductile and conventional construction).

Modal analysis was performed for each case to obtain the building's fundamental period of vibration $\left(\mathrm{T}_{\mathrm{a}}\right)$. A $5 \%$ damping ratio was assumed in the analyses. A reasonable assumption of members' stiffness is required to calculate the structure's fundamental period of vibration, and hence, to determine the building base shear, internal forces, and displacement demands under the design seismic loads (Adebar and Ibrahim 2002). In order to account for the cracking of $\mathrm{RC}$ elements, the member stiffness was reduced based on the effective cracked section properties taken as $20 \%$ of the slab gross moment of inertia. For the wall flexural and axial stiffnesses, the values of section property reduction factor, $\alpha_{w}$, given by CSA A23.3-14 (Canadian Standards Association CSA 2014) were calculated according to the equation:

$$
\alpha_{w}=1.0-0.35\left(\frac{R_{d} R_{o}}{\gamma_{w}}-1.0\right) \geq 0.5 \text { and } \leq 1.0
$$

where $\gamma_{w}$ may be taken equal to $R_{0}$. The value of $\alpha_{w}$ was calculated as $0.825,0.65$, and 0.5 for conventional, moderately ductile, and ductile walls, respectively. It is worth noting that the value of $\alpha_{w}$ in CSA A23.3-04 (2004) was 


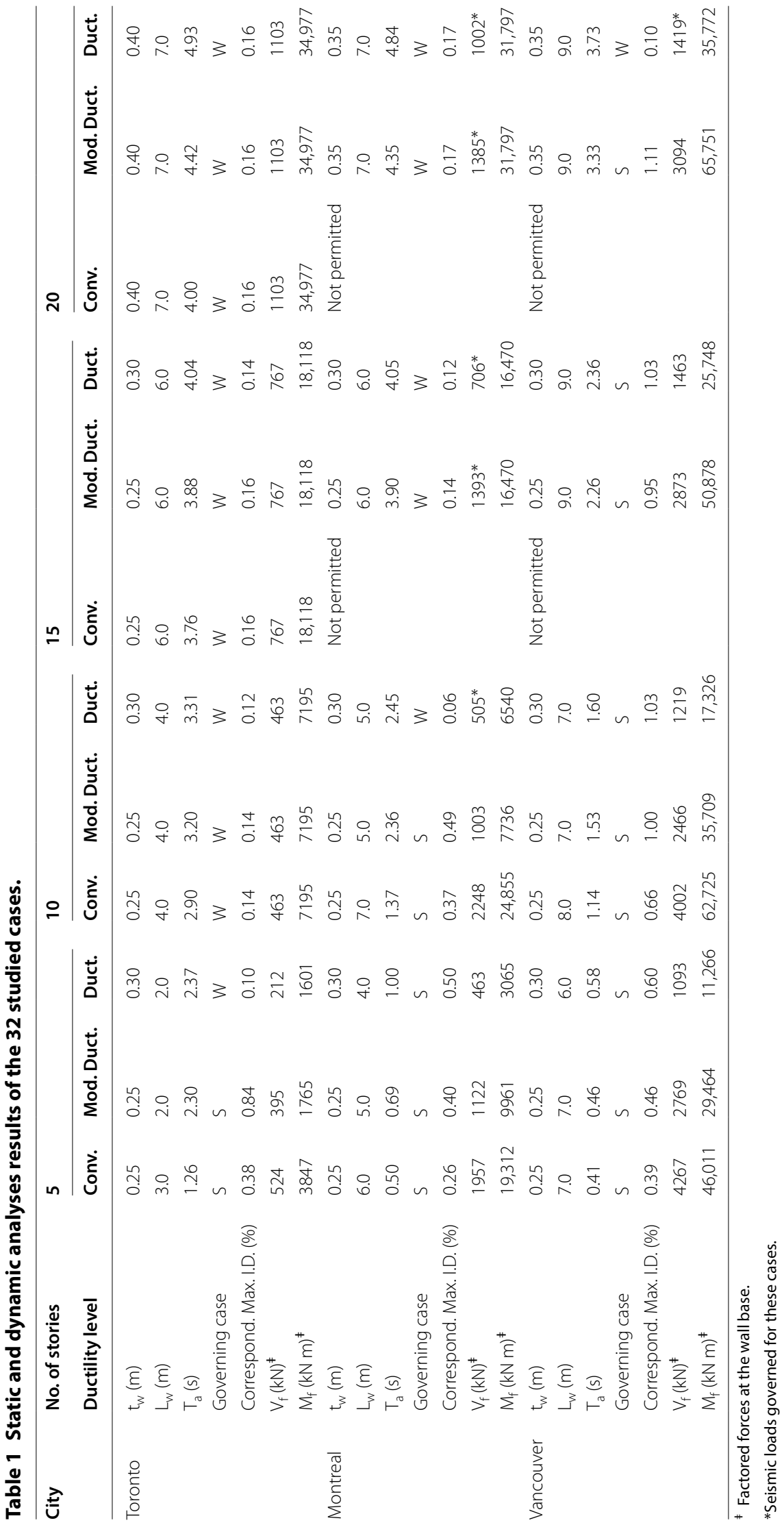




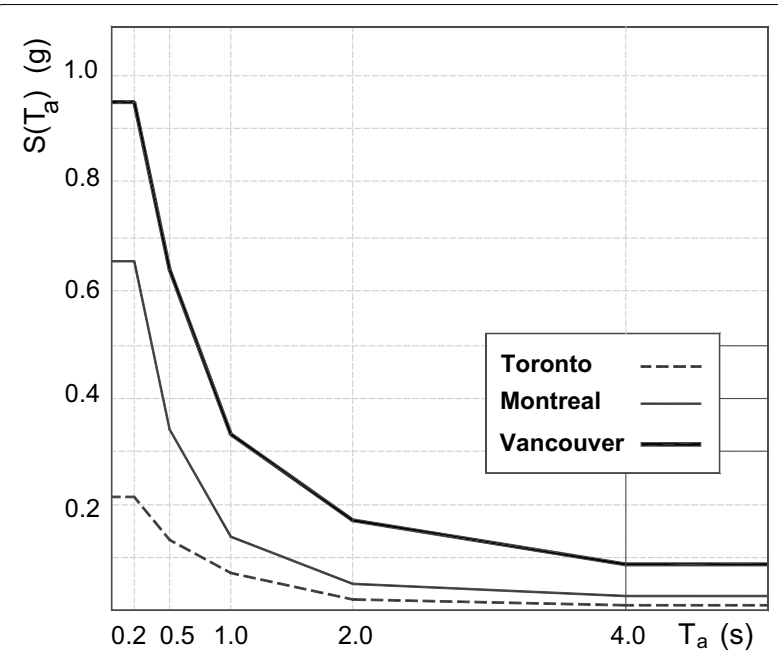

Fig. 3 The design response spectra of NBCC (2010) for Toronto, Montreal, and Vancouver.

taken as 0.7 for shear walls (assuming an axial load of $10 \%$ of the wall axial capacity) without any consideration of the wall ductility level. The shear wall foundation was modeled as fixed supports along the wall length. Similar to the shear wall design example in the Concrete Design Handbook (2005), the columns' stiffness were neglected in the numerical model, however, their weight was included in the building seismic weight. For the cases where gravity load resisting system need to be checked for the seismically induced deformations, another model that includes the gravity columns was created for each case. The building floors were assumed to act as rigid diaphragms in the lateral direction. The seismic weight per floor for the studied buildings ranged between 5200 and $5900 \mathrm{kN}$. The number of mode shapes considered in the analysis was taken as 12 , representing the first four mode shapes in the three directions $\left(\mathrm{U}_{\mathrm{x}}, \mathrm{U}_{\mathrm{y}}\right.$ and $\left.\mathrm{R}_{\mathrm{z}}\right)$. The sum of modal participating mass ratios (MPMR) in each direction considering the first four mode shapes was found to be at least 0.94 of the total mass, which exceeds the minimum required ratio of 0.90 according to the code.

The minimum accidental eccentricity $\left( \pm 0.1 \mathrm{D}_{\mathrm{nx}}\right)$ specified by NBCC (2010) was considered in the analyses, where $\mathrm{D}_{\mathrm{nx}}$ is the plan dimension of the building at level $\mathrm{x}$ normal to the seismic force direction. The dynamic analyses showed that the studied buildings are not sensitive to torsion due to the selected location of shear walls (on the building perimeter). Therefore, a minimum design base shear from the DAP equals to $80 \%$ of the base shear calculated using the ESP was considered as required by the code. It is worth noting that, the 3D modeling is needed in order to account for the torsional effects and to identify if the buildings are sensitive to torsion or not.
The design wind load acting on each building in each location was calculated. The factored base shear due to wind loads was compared to that due to earthquake loads. The wind loads were calculated using the Static Procedures of NBCC (2010) assuming the buildings were located in a rough terrain. The importance factors for wind and seismic load calculations were taken as 1.0, which represents a normal importance.

\subsection{Shear Wall Design}

The shear walls were designed according to the National Building Code of Canada (2010) and the new provisions of the Canadian Standard Association (CSA-A23.3-14) (2014). NBCC (2010) prohibits the conventional construction for shear wall buildings that are more than $40 \mathrm{~m}$ and $30 \mathrm{~m}$ high for Montreal and Vancouver cities, respectively. Therefore, shear walls designed as conventional construction were limited to 10 stories for Montreal and Vancouver, while for Toronto, there is no height limitation for RC shear wall buildings. The minimum wall thickness was taken as $\ell_{u} / 20$ for conventional construction (minimum of $250 \mathrm{~mm}$ ), $\ell_{u} / 14$ for moderately ductile walls, and $\ell_{u} / 10$ for ductile walls, where $\ell_{u}$ is the maximum unsupported height of the wall between two floors. NBCC (2010) limits the buildings' maximum interstorey drift (I.D.) ratio due to seismic loads to $2.5 \%$, while for the cases governed by wind loads, the maximum I.D. ratio due to the service wind loads is limited to $1 / 500$. The shear wall design was conducted using S-Concrete software (S-Frame Software Inc 2015) and respecting the aforementioned drift limits. The wall reinforcement was assumed to remain constant along the wall height (same as the plastic hinge region). The gravity columns were removed at the shear wall location as shown in Fig. 1. This is because having I-shaped walls has noticeably increased the walls' stiffness and consequently the seismic force attracted to the building.

For ductile and moderately ductile walls, the wall level of ductility at the plastic hinge region is achieved by ensuring that the inelastic rotational capacity of the wall, $\theta_{\text {ic }}$, exceeds the inelastic rotational demand, $\theta_{\text {id }}$, as required by CSA A23.3-14 (2014). $\theta_{\text {id }}$ is calculated as follows:

$$
\begin{aligned}
\theta_{i d}= & \frac{\Delta_{f} R_{d} R_{o}-\Delta_{f} \gamma_{w}}{h_{w}-\ell_{w} / 2} \geq 0.003 \text { for } \mathrm{R}_{\mathrm{d}}=2.0, \text { and } \\
& \geq 0.004 \text { for } \mathrm{R}_{\mathrm{d}}=3.5
\end{aligned}
$$

where $\Delta_{f} R_{d} R_{o}$ is the wall design displacement, $\Delta_{f} \gamma_{w}$ is the elastic portion of the wall displacement, $h_{w}$ is the wall total height, and $\ell_{w}$ is the wall length. $\theta_{\text {ic }}$ is calculated according to the equation: 


$$
\theta_{i c}=\frac{\varepsilon_{c u} \ell_{w}}{2 c}-0.002 \leq 0.025
$$

where $\mathrm{c}$ is the neutral axis distance, and $\varepsilon_{c u}$ is the concrete ultimate compressive strain taken as 0.0035 . If the wall rotational capacity was insufficient at the plastic hinge region, a special confinement reinforcement of the wall boundary elements has to be used.

Regardless of the ductility level used, the safety of members that are not part of the seismic force resisting system has to be ensured. The safety of gravity load resisting system was checked for each case against the seismically induced deformations according to $\mathrm{Cl}$. 21.11 of CSA-A23.3-14 (2014). For each of the studied cases, the shear wall design aimed that the building deformations due to seismic loads would not change the design of gravity columns when moderately ductile or ductile walls were used.

\subsection{Analysis Results}

Table 1 shows the results of the static and dynamic analyses for the 32 studied cases. The modal analysis of the studied buildings showed that the fundamental period of vibration $\left(\mathrm{T}_{\mathrm{a}}\right)$ for the 5 -storey buildings ranged between 0.41 and $2.37 \mathrm{~s}$, for the 10-storey buildings between 1.36 and $3.31 \mathrm{~s}$, for the 15 -storey buildings between 2.26 and $4.05 \mathrm{~s}$, and for the 20-storey buildings, $\mathrm{T}_{\mathrm{a}}$ ranged between 3.33 and $4.93 \mathrm{~s}$. $\mathrm{T}_{\mathrm{a}}$ from the modal analysis was compared to the empirical expression presented in NBCC (2010), and the fundamental period to be used in the ESP was chosen for each case. For shear wall buildings, $\mathrm{T}_{\mathrm{a}}$ used in the ESP cannot be greater than twice the empirical expression of NBCC (2010). The upper limit for $\mathrm{T}_{\mathrm{a}}$ used in the ESP was $0.76,1.28,1.74$, and $2.16 \mathrm{~s}$ for the 5-, 10-, 15- and 20-storey buildings, respectively. The values of $T_{a}$ from the modal analysis of the studied buildings are shown in Table 1.

The table shows the load case that governed the design of shear walls, denoted as (S) for the cases governed by seismic loads, and (W) for the cases governed by wind loads. The table also shows the maximum I.D. ratio of the building due to the governing case of loading. From the analyses, the maximum I.D. ratio due to unfactored seismic loads was $1.17 \%$ for the 20 -storey ductile building in Vancouver which is less than the $2.5 \%$ limit of the code. The maximum I.D. ratio due to unfactored wind loads was $0.17 \%$ which is less than the $0.2 \%$ limit of the code. The factored shear force, $V_{f}$, and factored bending moment, $\mathrm{M}_{\mathrm{f}}$, at the wall base were also given in Table 1. The building base shear due to seismic actions ranged between 0.004 and $0.039 \mathrm{~W}_{\mathrm{t}}$ for buildings in Toronto, 0.011-0.14 $\mathrm{W}_{\mathrm{t}}$ in Montreal, and 0.024-0.30 $\mathrm{W}_{\mathrm{t}}$ in Vancouver, where $\mathrm{W}_{\mathrm{t}}$ is the total seismic weight of the building.

Table 2 shows the overstrength ratios for shear force, $\mathrm{V}_{\mathrm{r}} / \mathrm{V}_{\mathrm{f}}$, and bending moment, $\mathrm{M}_{\mathrm{r}} / \mathrm{M}_{\mathrm{f}}$, calculated at the base of the walls, where $V_{r}$ and $M_{r}$ are the factored shear and moment resistance of the wall at the base. The shear force overstrength ratio at the wall base ranged between 1.00 and 3.83 , while the bending moment overstrength ratio at the wall base ranged between 0.95 and 2.40 . The high shear force and bending moment overstrength ratios for some cases were due to the increased dimensions of the walls in order to limit the building's drift for the safety of gravity columns under seismic loads. It can be noted that the wall nonlinear deformation $\left(\Delta_{f} R_{d} R_{o}\right)$ increases as the wall ductility level increases, even for the same wall dimensions and seismic hazard. This can be attributed to the stiffness reduction factor $\alpha_{w}$ given by CSA A23.3 (2014) in equation (1) which is a function of the value of $R_{d}$. Table 2 also shows the wall inelastic rotational demand due to factored seismic loads, $\theta_{\text {id }}$, and the inelastic rotational capacity of the wall, $\theta_{\mathrm{ic}}$, calculated at the wall plastic hinge region. To ensure a ductile behaviour as required by CSA A23.3-14 (2014), the wall inelastic rotational capacity (calculated using $\varepsilon_{\mathrm{cu}}=0.0035$ ) must exceed the wall inelastic rotational demand. Otherwise, special concrete confinement reinforcement is to be used at the wall boundary elements. In this study, no special confinement reinforcement was required for the studied buildings. The table gives the wall design displacement, $\Delta_{f} R_{d} R_{o}$, that is used for the calculation of $\theta_{\text {id }}$ and the wall global $\operatorname{drift}\left(\Delta_{f} R_{d} R_{o} / h_{w}\right)$.

\section{Ductility and Material Quantities}

The total amount of concrete and steel reinforcement material used in the walls construction for each building was calculated and shown in Table 3. The steel reinforcement weight per unit volume of concrete for shear wall construction ranged between 41 and $88 \mathrm{~kg} / \mathrm{m}^{3}$ for buildings in low seismic zones (Toronto), $66-105 \mathrm{~kg} / \mathrm{m}^{3}$ for medium seismic zones (Montreal), and $64-220 \mathrm{~kg} / \mathrm{m}^{3}$ for high seismic zones (Vancouver). The table shows that the shear walls designed in high seismic hazard zones had a high steel-to-concrete ratio when designed as conventional construction or moderately ductile systems. This is due to the high seismic hazard and the wall design that aimed to minimize the wall section so that the minimum seismic force would be attracted to the building. Therefore, more reinforcement is required for the wall to withstand the high moment and shear demands.

Table 3 also shows the total material cost estimate (concrete and steel reinforcement) for each of the studied cases. In order to have an estimate of the total material cost, the price of 1 ton of steel reinforcement bars was 


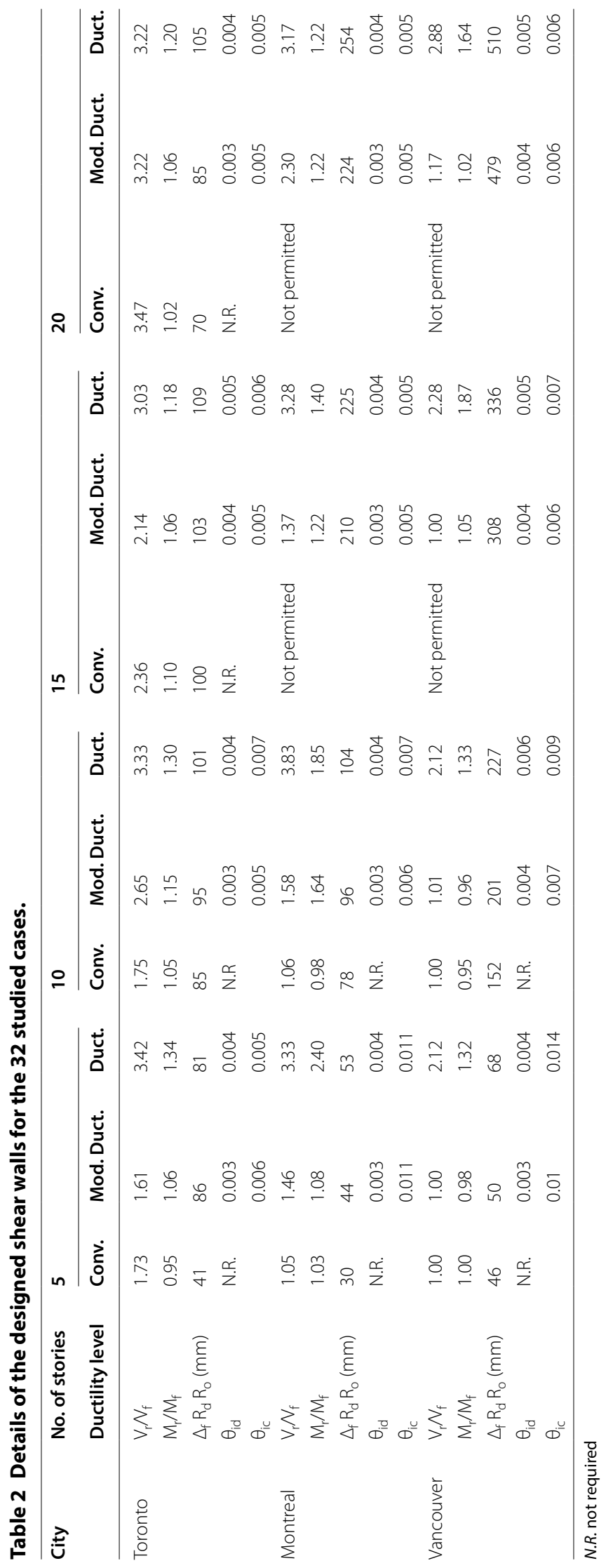




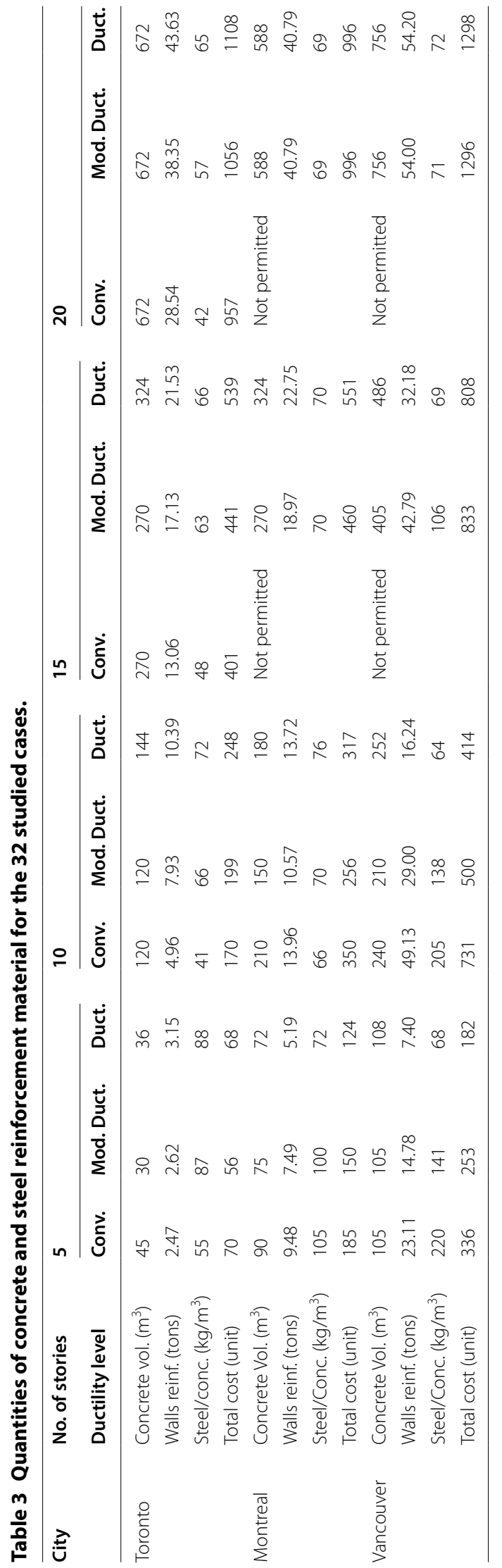


assumed to be equal to the price of $10 \mathrm{~m}^{3}$ of concrete. This value was an average value that was selected based on current concrete and steel reinforcement prices in Canada. The unit used for the total material cost given in the table represents the price of $1 \mathrm{~m}^{3}$ of concrete material, i.e., the total cost of concrete and steel material used for the conventional walls of the 5-storey building in Toronto is equal to 70 times the price of $1 \mathrm{~m}^{3}$ of concrete.

The quantities of concrete and steel material used for shear wall construction was compared to a reference case and shown in Fig. 4. The reference case was chosen to be the conventional construction for all buildings, except when conventional construction is not permitted by the code. In that case, the reference was the moderately ductile design.

From Fig. 4, it can be seen that for low seismic hazard zones, designing the walls as moderately ductile required the least material cost for low-rise buildings (represented by the 5 -story building in this study). A saving of $19 \%$ of the construction cost was achieved when moderately ductile walls were used compared to conventional construction. For medium- and high-rise buildings, the conventional construction required the least material quantities. For these buildings, the ductile design led to an increase of the walls' construction material by up to $20 \%$ more concrete and $109 \%$ more steel reinforcement. This is due to wind loads that governed the design of medium- and high-rise buildings in low seismic hazard zones, meanwhile imposing the stability and ductility requirements for ductile walls that are not required in this case.

In medium seismic hazard zones, designing the walls as ductile walls required the least material quantities for low-rise buildings. Designing the walls as ductile ones resulted in a saving of $33 \%$ in the material cost compared to the conventional construction, and $17 \%$ compared to the moderately ductile design. However, for mediumand high-rise buildings, the moderately ductile design led to the least material quantities due to the higher wind loads that governed the design in these cases. It should be noted that conventional construction is not permitted by NBCC (2010) for RC shear wall buildings higher than $40 \mathrm{~m}$ located in medium seismic hazard zones.

For high seismic hazard zones, the figure shows that ductile wall design required the least material cost for all of the studied cases. The ductile wall design provided a saving up to $46 \%$ in the material cost compared to conventional construction. The saving associated with the use of a ductile system is more noticeable for low-rise buildings. Moreover, the moderately ductile shear walls are not permitted for RC shear wall buildings higher than $60 \mathrm{~m}$ (20 stories) located in high seismic zones.
It is worth noting that the concrete and steel reinforcement quantities of the foundation system are generally proportional to those of the building's RC shear walls. The higher wall moment at the base would result in a bigger wall foundation with more reinforcement. Moreover, the formwork used in the shear wall construction will be directly affected by the concrete volume (shown in Table 3), i.e., the less amount of concrete used in the wall construction would reduce the formwork-related cost.

\section{Ductility and Rebar Constructability}

In addition to the amount of concrete and steel reinforcement material used for RC shear wall construction, the rebar work is another factor that affects the economy and constructability of RC buildings. Rebar work accounts for about $30 \%$ of the entire reinforcing cost for RC construction, and is also a time-consuming element of the construction process (Kang et al. 2013). Despite that ductile wall design involves stricter requirements that may increase the rebar work compared to conventional construction, the reduced design forces in case of ductile walls can result in a smaller amount of steel reinforcement (as was seen in Fig. 4), which could lead to less rebar work.

Figure 5 shows a sample reinforcement details for the 10-storey wall located in Montreal when designed as conventional construction, moderately ductile, and ductile systems. Table 4 shows the reinforcement details for each shear wall design of the studied cases; including the spacing of the $10 \mathrm{M}$ distributed vertical and horizontal reinforcement, $\mathrm{S}_{\mathrm{VL}}$ and $\mathrm{S}_{\mathrm{HZ}}$, the total amount of the concentrated reinforcement at the end zones, $\mathrm{As}_{\text {conc }}$, the spacing of the $10 \mathrm{M}$ hoops, $\mathrm{S}_{\mathrm{Hoops}}$, and the length of the confined end zone, $\mathrm{L}_{\mathrm{COL}}$. In order to evaluate the rebar work associated with each level of ductility, the total number of bar bends, B., bar cuts, C., and tie wraps, T., used in the construction of one wall were calculated for each of the studied cases. This number (noted as the rebar constructability factor, C.F.) can reflect the complexity of assembling the wall reinforcement cages which is one of the main factors affecting the constructability of RC buildings (Kang et al. 2013). In the calculation of the proposed C.F., the time and complexity of each of the three procedures were assumed to be equal. Table 4 shows the data required for the calculation of the C.F. for each shear wall design. The C.F. for each ductility level was compared to a reference value, which is the conventional construction case, except when conventional construction is not permitted by the code. In that case, the moderately ductile design was the reference case. The values of the C.F. compared to the reference case are depicted in Fig. 6 for each building height and location. 


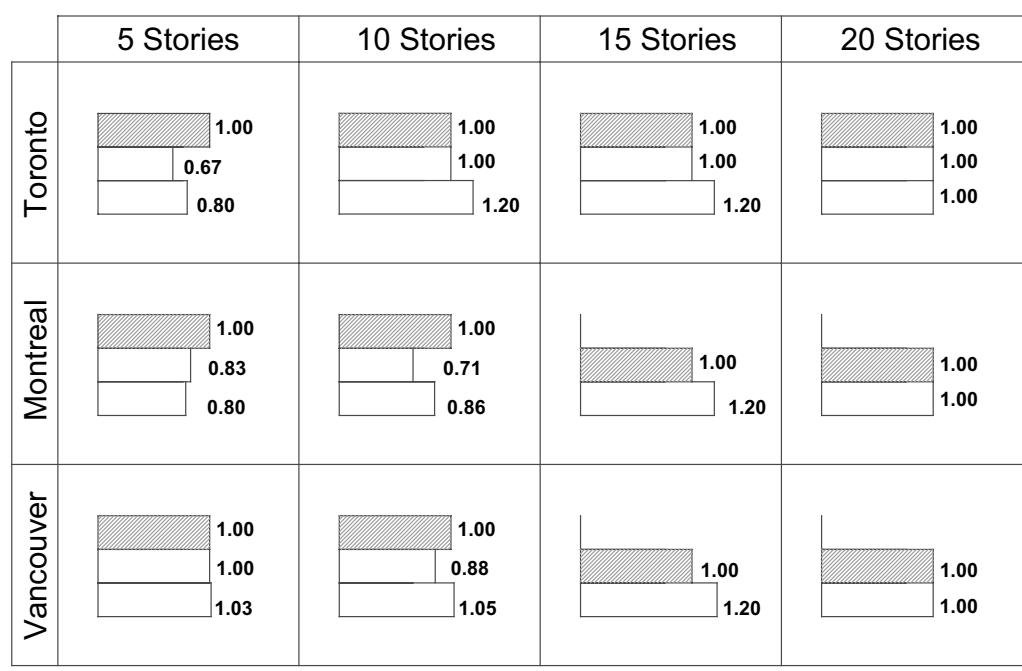

\section{Concrete}

material

(relative)

\begin{tabular}{|l|}
\hline Conventional \\
\hline Mod. Ductile \\
\hline Ductile \\
\hline
\end{tabular}

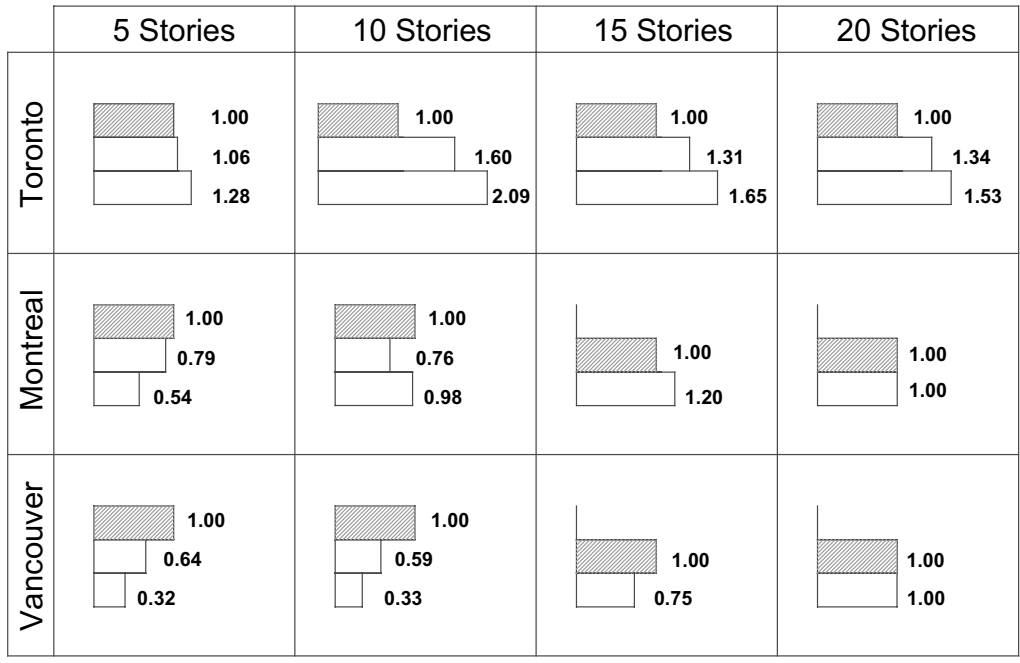

Reinforcement

material

(relative)

Conventional Mod. Ductile Ductile

\begin{tabular}{|c|c|c|c|c|}
\hline & 5 Stories & 10 Stories & 15 Stories & 20 Stories \\
\hline \multirow{3}{*}{$\begin{array}{l}\text { 욷 } \\
\text { 임 } \\
\text { 은 }\end{array}$} & S. 1.00 & WI 1.00 & W 1.00 & W/ 1.00 \\
\hline & \begin{tabular}{l|l}
$\mathrm{S}$ & 0.81
\end{tabular} & W 1.18 & W 1.10 & $w_{1.10}$ \\
\hline & w 0.97 & W 1.46 & $\begin{array}{ll}\mathrm{W} & 1.35\end{array}$ & $\begin{array}{ll}\mathrm{w} & 1.16\end{array}$ \\
\hline \multirow{3}{*}{ 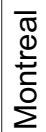 } & S. 1.00 & S. 1.00 & & \\
\hline & \begin{tabular}{l|l}
$\mathrm{S}$ & 0.81
\end{tabular} & \begin{tabular}{l|l}
$\mathrm{S}$ & 0.73
\end{tabular} & W 1.00 & W/ 1.00 \\
\hline & \begin{tabular}{l|l} 
S & 0.67
\end{tabular} & w 0.91 & W 1.20 & W 1.00 \\
\hline \multirow{3}{*}{ 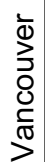 } & S 1.00 & S. 1.00 & & \\
\hline & S $\quad 0.75$ & \begin{tabular}{l|l}
$\mathrm{S}$ & 0.68
\end{tabular} & S. 1.00 & S. 1.00 \\
\hline & \begin{tabular}{l|l}
$\mathrm{S}$ & 0.54
\end{tabular} & \begin{tabular}{l|l}
$S$ & 0.57
\end{tabular} & $\mathrm{~S} 0.97$ & W 1.00 \\
\hline
\end{tabular}

Total material (relative) \begin{tabular}{|l|}
\hline Conventional \\
\hline Mod. Ductile \\
\hline Ductile \\
\hline
\end{tabular}

Fig. 4 The construction material quantities relative to a reference case. 


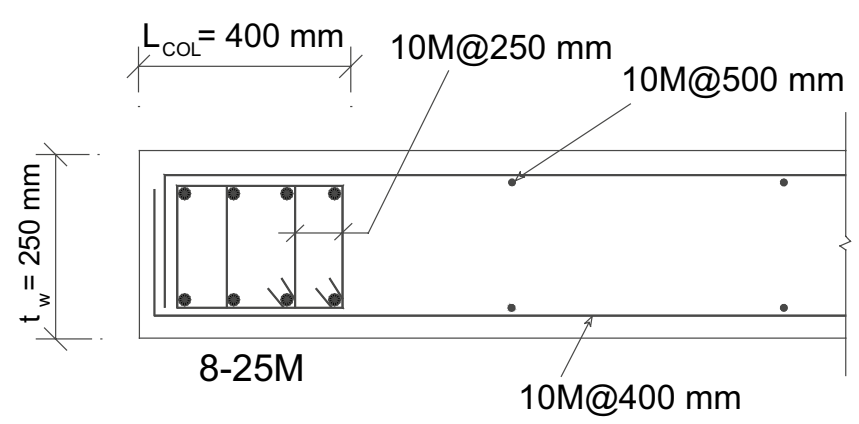

\section{Conventional Construction}

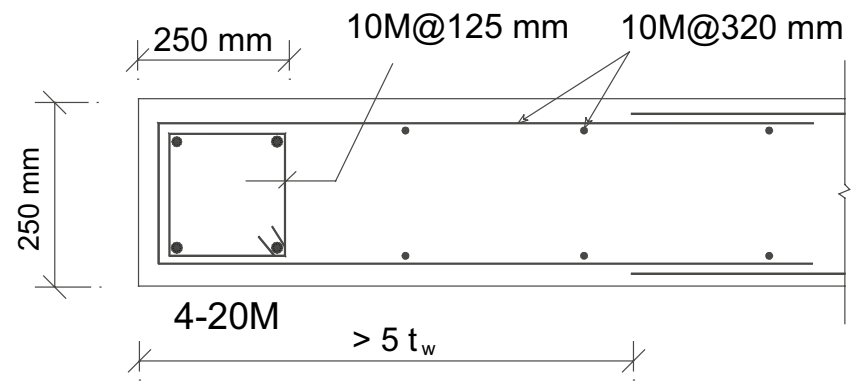

Moderately Ductile

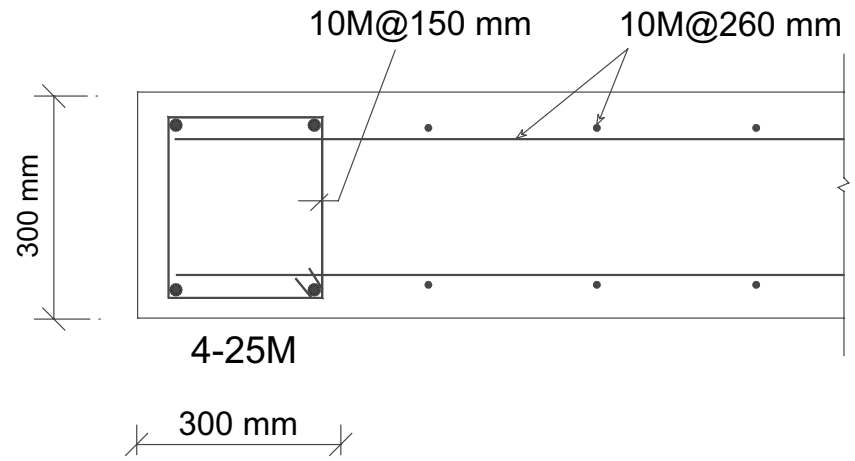

Ductile

Fig. 5 Reinforcement details of the 10-storey shear walls in Montreal.

From the figure, it can be seen that conventional construction design required the least rebar work for shear wall buildings located in low and medium seismic hazard zones when conventional construction design is allowed by the code. However, for high seismic hazard zones, the ductile wall design showed the least rebar work when the wall design is governed by the seismic loads.

The results of the current study can be used for the selection of the most suitable ductility level for RC shear wall buildings located in similar seismic hazard zones. According to the relative cost of construction material, formwork, and rebar work, the engineer can decide which ductility level would be the economic choice for a specific building height and location. However, the conclusions derived in this study would be applicable for buildings with similar dimensions and occupancies. In order to generalize the conclusions, more analyses are to be conducted for other cases to account for the effect of soil condition, number and value of the building spans, and the location of walls on the building floor plan. The analyses in this study were conducted for buildings located in three cities that represent three different seismic hazard zones in Canada. The conclusions derived from these analyses can be applicable for other locations or countries with similar seismic hazard and for shear wall buildings with seismic force reduction factors similar to those of the NBCC (2010).

\section{Conclusions}

Four multi-storey reinforced concrete (RC) shear wall buildings with different heights located in three different cities in Canada were selected. The cities were selected to represent three different seismic hazard zones (low, medium and high). For each building height 


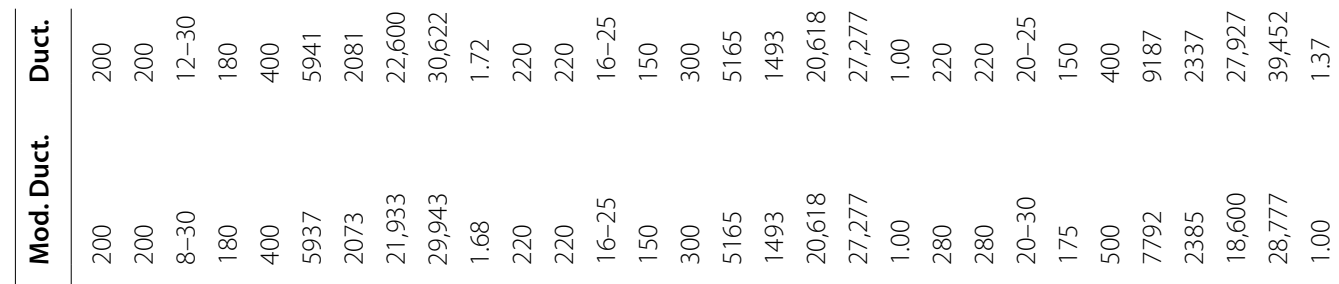
¿

范

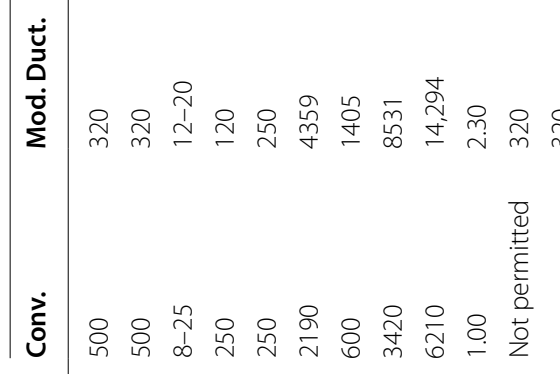

|艹 ثัญ

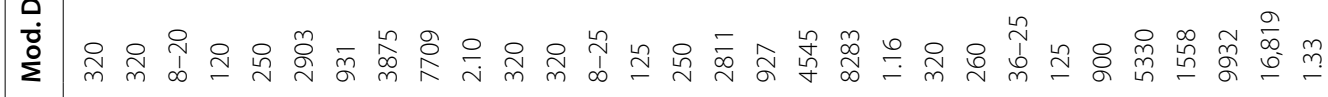
-

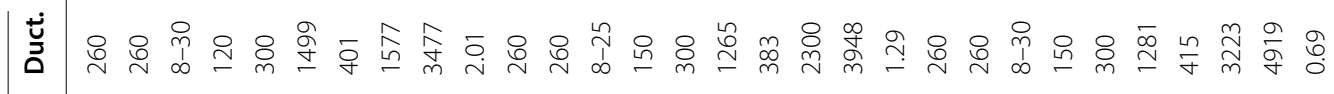
节

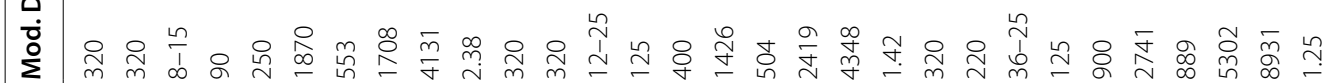
远

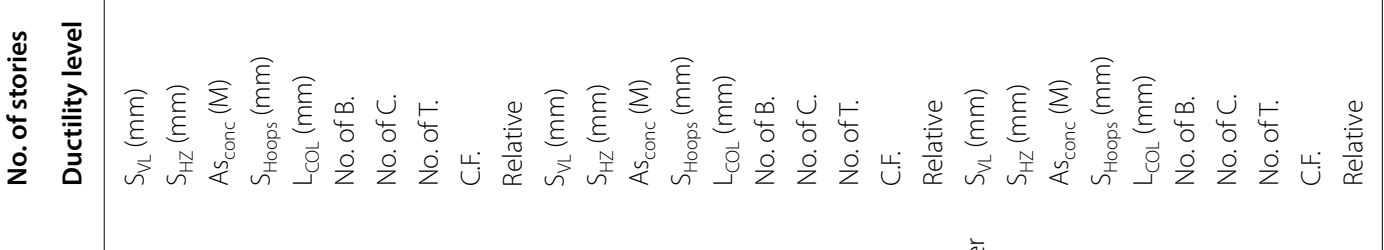




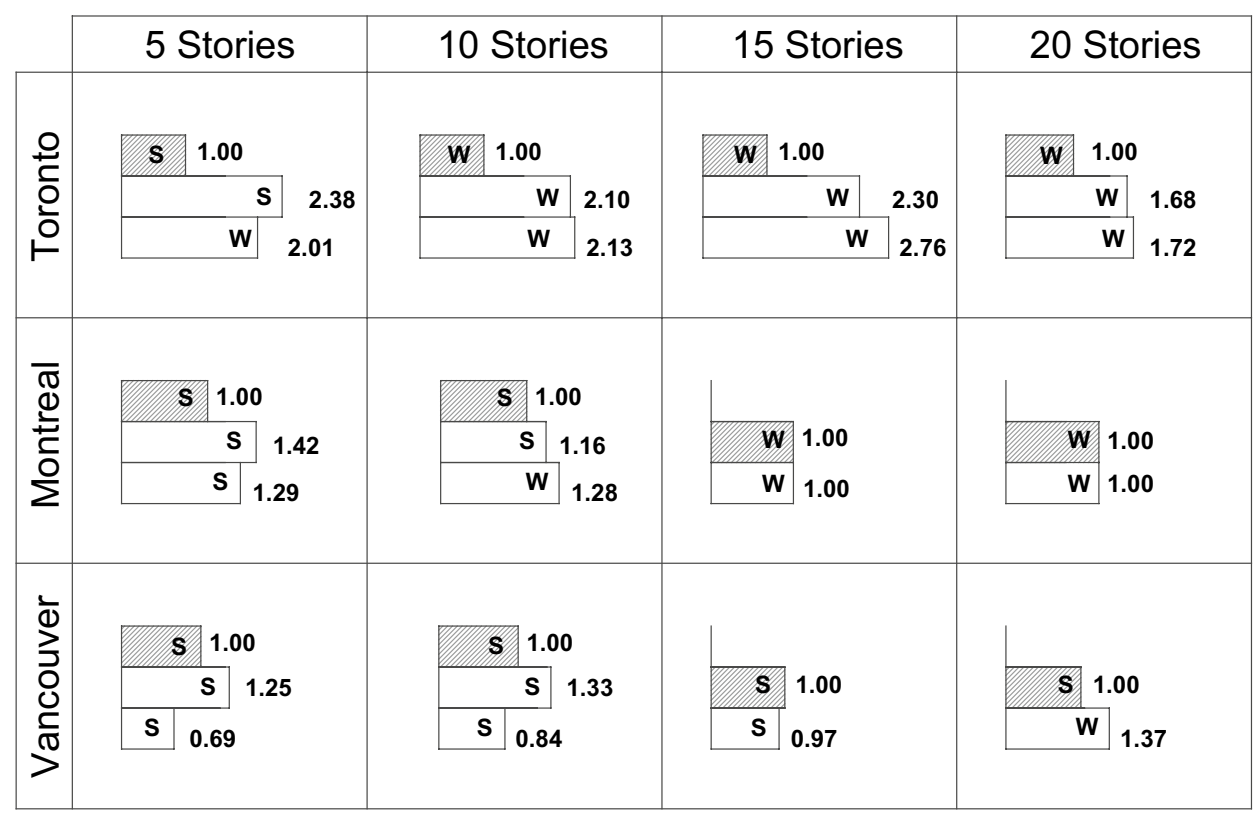

\begin{tabular}{|l|}
\hline Conventional \\
\hline Mod. Ductile \\
\hline Ductile \\
\hline
\end{tabular}

Fig. 6 The rebar constructability factor (C.F.) relative to a reference case.

and location, the shear walls were designed as ductile, moderately ductile, or conventionally constructed systems. In low seismic hazard zones, it was found that conventional construction design required the least construction material quantities for medium- and highrise shear wall buildings (10-storey high or more). However, for low-rise buildings (represented by the 5 -storey building), a saving of $19 \%$ in the construction material cost was achieved when moderately ductile walls were used. In medium seismic hazard zones, the moderately ductile design required the least material quantities for medium- and high-rise shear wall buildings, while for the low-rise buildings, a saving of $33 \%$ in the material cost was achieved when ductile design was applied. In high seismic hazard zones, the ductile wall design required the least material cost for all building heights. They provided a saving up to $46 \%$ of the total material cost compared to the conventional construction.

The analyses and design results showed that conventional construction design required the least rebar work for RC shear wall buildings located in low and medium seismic hazard zones when conventional construction design is permitted by the code. However, for high seismic hazard zones, the ductile wall design showed the least rebar work. Given the material quantity estimate and the rebar work associated with each ductility level for a certain building height and location, the structural engineer can decide the most economical and constructible design for RC shear wall buildings at the conceptual design stage.
Authors' contributions

HE carried out the numerical and analytical studies, and drafted the manuscript. KG participated in the paper interface and reviewed the manuscript drafts. Both authors read and approved the final manuscript.

\section{Author details}

1 Department of Building, Civil and Environmental Engineering, Concordia University, 1515 St. Catherine West, Montreal H3G 2W1, Canada. ${ }^{2}$ Department of Structural Engineering, Ain Shams University, 1 ElSarayat Street, El-Abbaseya, Cairo 11517, Egypt.

\section{Acknowledgements}

The financial support of the Natural Science and Engineering Research Council of Canada (NSERC) is highly appreciated. The authors also would like to thank Stantec for their support through this research project.

\section{Publisher's Note}

Springer Nature remains neutral with regard to jurisdictional claims in published maps and institutional ailiations.

Received: 10 March 2017 Accepted: 16 April 2018

Published online: 26 July 2018

\section{References}

Adebar, P., Bazargani, P., Mutrie, J., \& Mitchell, D. (2010). Safety of gravity-load columns in shear wall buildings designed to Canadian standard CSA A23.3. Canadian Journal of Civil Engineering, 37(11), 1451-1461.

Adebar, P., \& Ibrahim, A. (2002). Simple nonlinear flexural stiffness model for concrete structural walls. Journal of Earthquake Spectra, 18(3), 407-426.

Adebar, P., Mutrie, J. De Vall, R., and Mitchell, D. (2014). Seismic design of concrete buildings: The 2015 Canadian building code. In Proceedings of the 10th U.S. National Conference on Earthquake Engineering, Earthquake Engineering Research Institute, Anchorage, AK.

Adebar, P., Mutrie, J., \& DeVall, R. (2005). Ductility of concrete walls: The Canadian seismic design provisions 1984 to 2004. Canadian Journal of Civil Engineering, 32(6), 1124-1137. 
Boivin, Y., \& Paultre, P. (2010). Seismic performance of a 12-storey ductile concrete shear wall system designed according to the 2005 National Building Code of Canada and the 2004 Canadian Standard Association Standard A23.3. Canadian Journal of Civil Engineering, 37(1), 1-16.

Canadian Standards Association CSA. (2004). Design of concrete structures A23.3-04, Mississauga, Ontario, Canada.

Canadian Standards Association CSA. (2014). Design of concrete structures A23.3-14, Mississauga, Ontario, Canada.

Choopool, N., \& Boonyapinyo, V. (2011). Seismic performance evaluation of reinforced concrete moment resisting frames with various ductility in low seismic zone. American Journal of Engineering and Applied Sciences, 4(1), 17-36.

CSA CAN/CSA-A23.3-04 (2005). Concrete design handbook. Ottawa (Ontario): Canadian Portland Cement Association.

CSI. (2013). Analysis reference manual for SAP2000, ETABS, and SAFE. California: Computers and Structures Inc.

Filiatrault, A., Lachapelle, E., \& Lamontagne, P. (1998). Seismic performance of ductile and nominally ductile reinforced concrete moment resisting frames. I. Experimental study. Canadian Journal of Civil Engineering, 25(2), $331-341$.

Galal, K., \& El-Sokkary, H. (2008). Analytical evaluation of seismic performance of RC frames rehabilitated using FRP for increased ductility of members. Journal of Performance of Constructed Facilities (ASCE), 22(5), 276-288.

Heidebrecht, A., \& Naumoski, N. (1999). Seismic performance of ductile medium height reinforced concrete frame buildings design in accordance with the provisions of the 1995 National Building Code of Canada. Canadian Journal of Civil Engineering, 26(5), 606-617.
Hutchison, D., \& Van Geldermalsen, T. (1983). Optimum design of reinforced concrete shear walls. Bulletin of the New Zealand National Society for Earthquake Engineering, 17(3), 185-197.

NBCC (2010). National Building Code of Canada. Associate Committee on the National Building Code, National Research Council of Canada, Ottawa, Ontario.

Paulay, T., Priestley, M., \& Synge, A. (1982). Ductility in earthquake resisting squat shear walls. ACl Journal, 79(4), 257-269.

Priestley, M., \& Park, R. (1987). Strength and ductility of concrete bridge columns under seismic loading. ACl Structural Journal, 84(1), 61-76.

Pullmann, T., Skolicki, Z., Freischlad, M., Arciszewski, T., De Jong, K., SchnellenbachHeld, M. (2003). Structural design of reinforced concrete tall buildings: Evolutionary computation approach using fuzzy sets. In Proceedings of the 10th International Workshop of the European group for intelligent computing engineering, Delft, Netherlands, pp. 53-61.

Sadjadi, R., Kianoush, M., \& Talebi, S. (2007). Seismic performance of reinforced concrete moment resisting frames. Engineering Structures, 29(9), 2365-2380.

Wallace, J. (1994). New methodology for seismic design of RC shear walls. Journal of Structural Engineering, 120(3), 863-884.

S-Frame Software Inc. (2015). S-concrete: Concrete section design, version 11.00.31. Maycrest Way, Richmond, B.C., Canada.

Kang, S., Park, S., Jang, S., Jin, J., Eom, T., \& Park, H. (2013). Constructability and economic evaluation of continuous hoop reinforcement method. Journal of the Korea Institute of Building construction, 13(3), 291-305.

\section{Submit your manuscript to a SpringerOpen ${ }^{\circ}$ journal and benefit from:}

- Convenient online submission

- Rigorous peer review

- Open access: articles freely available online

- High visibility within the field

- Retaining the copyright to your article

Submit your next manuscript at $\boldsymbol{\sim}$ springeropen.com 